\title{
EchoGéo
}

$13 \mid 2010$

Afrique, 50 ans d'indépendance : État et territoires

\section{Célébrer l'ordinaire : vues de Yeoville par ses habitants}

\section{Claire Bénit-Gbaffou, Sophie Didier et Naomi Roux}

\section{OpenEdition}

Journals

Édition électronique

URL : https://journals.openedition.org/echogeo/12027

DOI : $10.4000 /$ echogeo. 12027

ISSN : 1963-1197

Éditeur

Pôle de recherche pour l'organisation et la diffusion de l'information géographique (CNRS UMR 8586)

Référence électronique

Claire Bénit-Gbaffou, Sophie Didier et Naomi Roux, «Célébrer l'ordinaire : vues de Yeoville par ses habitants », EchoGéo [En ligne], 13 | 2010, mis en ligne le 20 septembre 2010, consulté le 03 août 2021. URL : http://journals.openedition.org/echogeo/12027 ; DOI : https://doi.org/10.4000/echogeo. 12027

Ce document a été généré automatiquement le 3 août 2021.

EchoGéo est mis à disposition selon les termes de la licence Creative Commons Attribution - Pas d'Utilisation Commerciale - Pas de Modification 4.0 International (CC BY-NC-ND) 


\section{Célébrer l'ordinaire : vues de Yeoville par ses habitants}

Claire Bénit-Gbaffou, Sophie Didier et Naomi Roux

\section{NOTE DE L'AUTEUR}

Yeoville studio is a research and learning initiative driven by a collaboration between the Wits University School of Architecture and Planning and the Yeoville Stakeholders Forum, supported by several other partners. It aims to produce quality academic research that is relevant, useful and of interest to the Yeoville community. 
Illustration 1 - The Ridge, Johannesburg, 2010

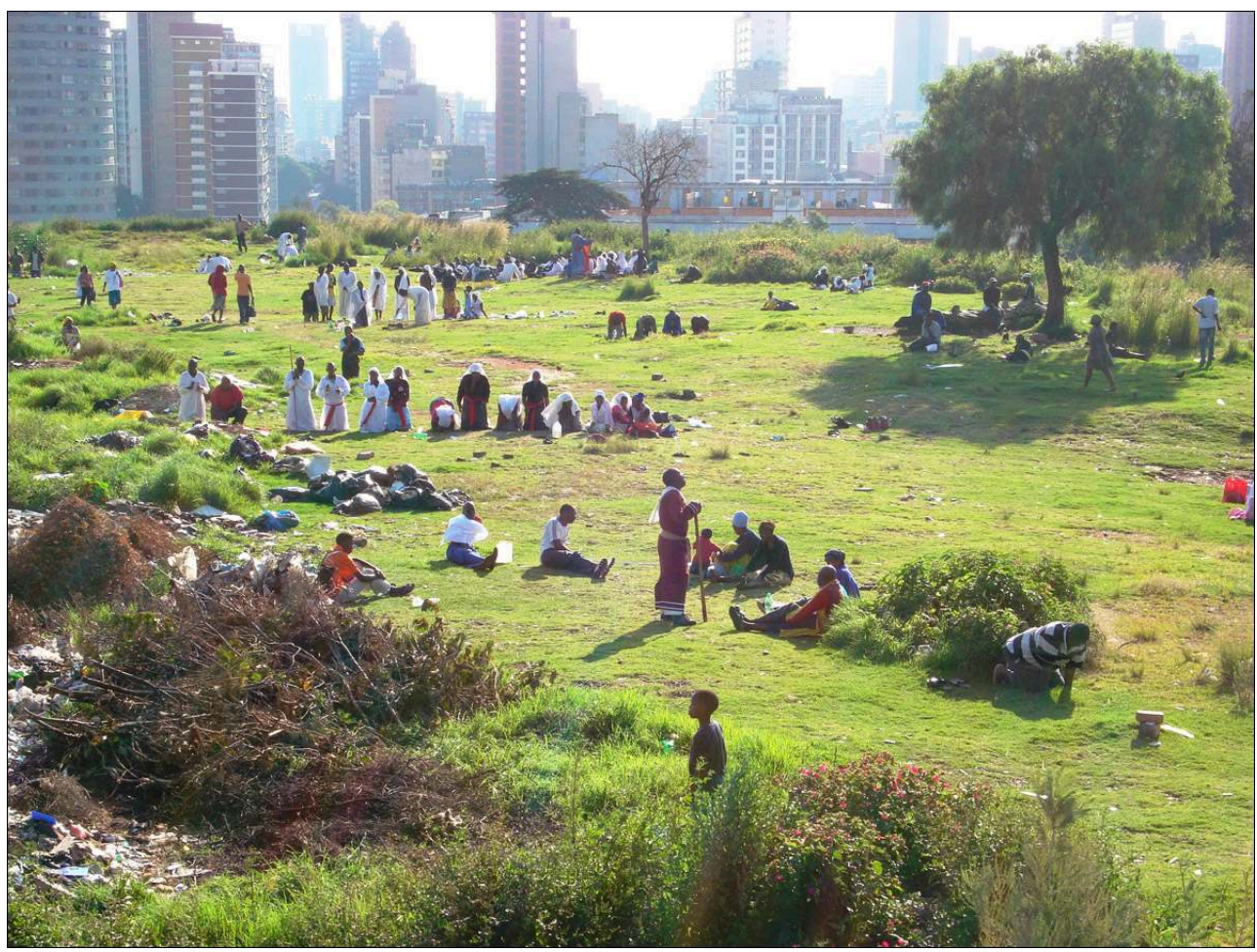

1 Cette photographie, prise par un étudiant de troisième année à la School of Architecture and Planning de Wits dans le cadre du projet de recherche/action Yeoville Studio, représente "The Ridge » à Johannesburg. The Ridge marque la frontière entre le quartier de Yeoville et les quartiers denses de Berea et Hillbrow (arrière plan de la photo) dans l'inner city. Cet espace interstitiel est un lieu privilégié pour les pratiques religieuses des résidents des alentours, particulièrement le dimanche.

2 La photographie, ainsi que cinq autres prises par les résidents de Yeoville lors d'un travail de photographie participative sur leur modes d'habiter, a été plébiscitée par les résidents à la suite d'une exposition publique (voir les étiquettes de couleurs apposées sur la photo) et une série de cartes postales gratuites a été éditée à partir de ces photos. 
Illustration 2 - Présentation de la photographie lors d'une exposition publique

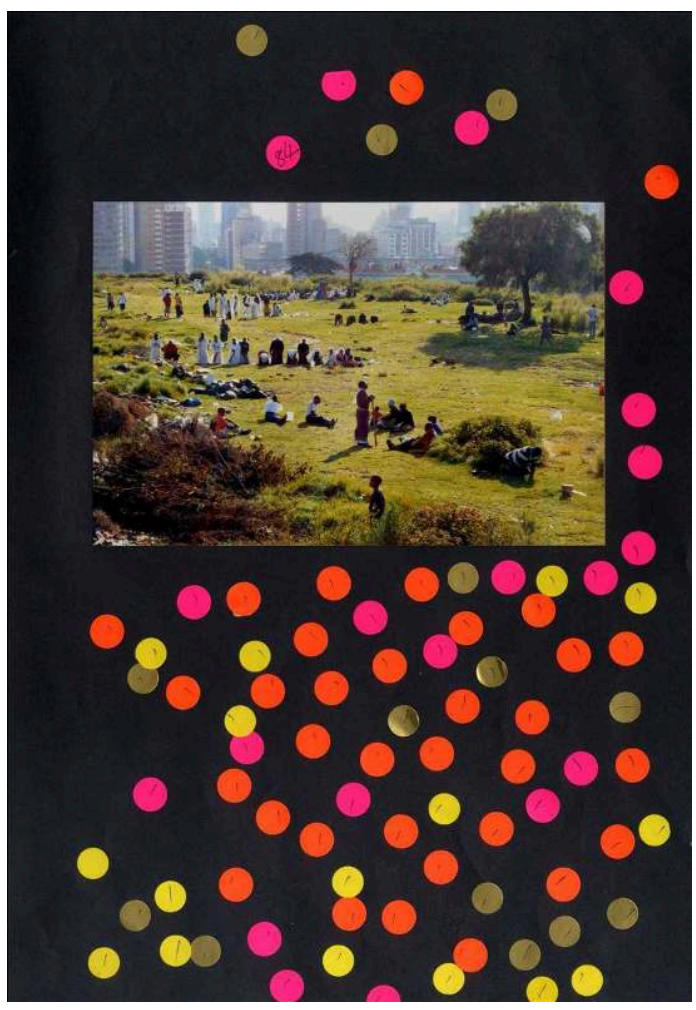

3 Au final, la sélection opérée nous donne à voir les hauts lieux comme les pratiques ordinaires des résidents de ce quartier stigmatisé en périphérie du centre-ville de Johannesburg.

4 Pour plus d'information sur le projet Yeoville Studio, voir http://web.wits.ac.za/ Academic/EBE/ArchPlan/YeovilleStudio.htm

5 Pour voir l'intégralité des photos sélectionnées, voir http://web.wits.ac.za/NR/ rdonlyres/E95F395F-A5EF-47E2-80C2-DEC5E50ADFBD/0/Yeovillepostcards.pdf

\section{AUTEURS}

\section{CLAIRE BÉNIT-GBAFFOU}

Ecole d'Urbanisme et d'Architecture, Wits University, Afrique du Sud, Claire.Benit-

Gbaffou@wits.ac.za

\section{SOPHIE DIDIER}

Institut Français d'Afrique du Sud, UMIFRE CNRS n² 25 - USR 3336 Johannesburg,

sophie@ifas.org.za 
NAOMI ROUX

Laboratoire CUBES, Ecole d'Urbanisme et d'Architecture, Wits University, Afrique du Sud, Naomi.Roux@wits.ac.za 